\title{
Densidade mineral óssea em cadelas submetidas à ovarioisterectomia com e sem reposição estrogênica oral
}

[Mineral density in bones of ovariohysterectomized bitches, with or without oral estrogen replacement]

\author{
C. Schmidt ${ }^{1}$, S.R.V.S. Franco ${ }^{2}$, L.C. Vulcano ${ }^{2}$, C.L.B. Godoy ${ }^{3}$, A.G. Raiser ${ }^{1}$ \\ ${ }^{1}$ Departamento de Clínica de Pequenos Animais - UFSM \\ Faixa de Camobi, km 9 \\ 97105-900 Santa Maria, RS \\ ${ }^{2}$ Faculdade de Medicina Veterinária e Zootecnia - UNESP- Botucatu, SP \\ ${ }^{3}$ Departamento de Clínica de Grandes Animais - UFSM - Santa Maria, RS
}

\begin{abstract}
RESUMO
Estudaram-se os efeitos da ovarioisterectomia na densidade mineral óssea de cadelas e da reposição de estrógenos após a cirurgia. Foram utilizadas 12 cadelas, sem raça definida, entre dois e seis anos de idade e pesos entre 5 e $15 \mathrm{~kg}$. Os animais, submetidos à ovarioisterectomia, foram separados em dois grupos de seis. Um grupo serviu como controle, e o outro recebeu estrógenos naturais conjugados na dose de $0,01 \mathrm{mg} / \mathrm{kg}$ via oral a cada 48 horas, durante 12 meses. No dia da cirurgia e após 12 meses, foram feitas radiografias com vistas à densitometria óptica em imagem radiográfica. A ovarioisterectomia diminuiu a densidade óssea, e a reposição estrogênica, na dose utilizada, foi capaz de preservá-la.
\end{abstract}

Palavras-chave: cadela, ovarioisterectomia, estrógeno, densidade óssea, reposição hormonal

\begin{abstract}
Effects on bone density of ovariohysterectomy and post-operative estrogen replacement were studied in bitches. Twelve mixed-breed bitches, ranging from 2 to 6 years of age and weighing between 5 and $15 \mathrm{~kg}$ were submitted to ovariohysterectomy and separated in two groups of six, after a period of adaptation of 60 days. Bitches from the first group were an un-innoculated control; whereas treated bitches received $0.01 \mathrm{mg} / \mathrm{kg}$ per os of natural estrogen every 48 hours for 12 months. Radiographs were taken on the day of surgery and 12 months later. Variation in bone density was quantified by optic densitometry in radiographic images. Ovariohysterectomy decreased bone density, whereas estrogen replacement moderated the effect.
\end{abstract}

Keywords: bitch, ovariohysterectomy, estrogen, bone density, hormone replacement

\section{INTRODUÇ̃̃O}

Em animais adultos, as alterações ósseas após a ovarioisterectomia são semelhantes àquelas encontradas em mulheres após a menopausa ou após a gonadectomia, em que a densidade mineral óssea decresce rapidamente devido à hipoestrogenemia, o que resulta em deterioração da microarquitetura óssea e, conseqüentemente, aumento no risco de fraturas (Speroff et al., 1996), em razão do desequilíbrio entre a formação e a reabsorção óssea (Malluche et al., 1986).

Sabe-se que os estrógenos podem atuar sobre o metabolismo e a remodelação óssea por mecanismos indiretos, afetando a concentração dos hormônios calciotrópicos, e por mecanismos

Recebido em 3 de agosto de 2004

Aceito em 16 de dezembro de 2005

E-mail: dete.s@via-rs.net 
diretos, atuando sobre receptores específicos nas células ósseas (Parra, 2001). O estrógeno diminui a sensibilidade óssea ao paratormônio (PTH), aumenta a atividade da hidroxilase renal e a absorção intestinal de cálcio (Gray, 2001; Parra, 2001). Nas células ósseas, diminui a síntese de interleucina-1, interleucina-6 e fator de necrose tumoral, que agem sobre os osteoblastos e estimulam o processo de diferenciação de osteoclastos a partir de células precursoras da medula óssea (Ardilla, 2001a; Ardilla 2001b; Parra, 2001).

Em diferentes estudos, cadelas adultas submetidas à ooforectomia ou ovarioisterectomia apresentaram maior número de espaços de reabsorção óssea por $\mathrm{mm}^{2}$ quando comparadas a cadelas intactas (Snow et al., 1984; Karambolova et al.,1985; Malluche et al., 1986; Danucci e Patterson, 1987).

O uso da reposição estrogênica em beagles castradas resultou na preservação da massa de osso cortical quando comparadas às beagles castradas sem reposição (Snow et al., 1984; Karambolova et al., 1987). Entretanto, Doige e Weisbrode (1998) citaram que a osteopenia na cadela castrada é transitória e que esses animais não aumentam o risco de desenvolver osteoporose.

Radiografias convencionais não são suficientes para detectar mudanças menores que $30 \%$ na mineralização óssea; para isso, são necessários métodos mais acurados (Garton et al., 1994).

O objetivo deste trabalho foi o de estudar a densidade mineral óssea de cadelas submetidas à ovarioisterectomia, recebendo ou não reposição com estrógenos.

\section{MATERIAL E MÉTODOS}

Foram utilizadas 12 cadelas adultas, sem raça definida, entre dois e seis anos e pesos entre 5 e $15 \mathrm{~kg}$. Na chegada, os animais foram submetidos a exame clínico completo e exames de laboratório de rotina (hemograma, urinálise, uréia, creatinina e alanina aminotransferase) visando descartar possíveis afecções. Durante o período de adaptação, que durou 60 dias, os animais receberam vermífugo, agente pulicida e foram vacinados contra as principais doenças infectocontagiosas caninas. Foram mantidos com água à vontade e ração comercial fornecida baseada em tabela nutricional referenciada por Kirk (1988).

Após a fase de adaptação, as cadelas foram submetidas à ovarioisterectomia. No mesmo dia, foram realizadas as primeiras tomadas radiográficas (M1). Os animais foram, então, separados em dois grupos de seis, um deles submetido à reposição hormonal $(\mathrm{RH})$ e o outro usado como controle (C).

Cada grupo foi mantido em um canil coletivo e, após 15 dias da cirurgia, foi iniciada a reposição estrogênica. $\mathrm{O}$ grupo $\mathrm{RH}$ recebeu $0,01 \mathrm{mg} / \mathrm{kg}$ de estrógenos naturais conjugados ${ }^{1}$ via oral, preparados em solução de azeite de oliva, a cada 48 horas, durante 365 dias. O grupo-controle recebeu apenas o azeite de oliva como placebo. Após esse período, novas tomadas radiográficas foram realizadas (M 2).

Utilizou-se aparelho de raios-X com potência de $100 \mathrm{kV}$ (quilovolts) e $200 \mathrm{~mA}$ (miliamperes), filmes radiográficos ${ }^{2}$ de $18 \times 24 \mathrm{~cm}$ e chassi de tamanho correspondente, no qual foi fixada uma escala de alumínio (penetrômetro ou phantom), composta por 20 degraus, medindo o primeiro $0,5 \mathrm{~mm}$ de espessura, variando a seguir de $0,5 \mathrm{em}$ $0,5 \mathrm{~mm}$, tendo cada degrau área de $15 \times 5 \mathrm{~mm}$.

As radiografias foram obtidas do membro anterior direito na região do terço distal do rádio e ulna dos cães, em projeção craniocaudal, empregando-se $45 \mathrm{kV}$ e $3,5 \mathrm{~mA}$, com distância focofilme de $90 \mathrm{~cm}$. A região de interesse foi posicionada paralela ao phantom, a $3 \mathrm{~cm}$ dele, tendo-se o cuidado de manter essa estrutura coincidindo com a porção média do phantom. $\mathrm{O}$ feixe principal de raios $\mathrm{X}$ foi centrado sobre uma marca no chassi, que determinava o meio entre o penetrômetro e a estrutura óssea (Fig. 1).

Para o processo de revelação e fixação, foi utilizada processadora automática padrão ${ }^{3}$. Os exames radiográficos foram realizados antes do início (M1) e no final do experimento (M2), com intervalo de 12 meses.

\footnotetext{
${ }^{1}$ Premarim. Laboratórios Wyeth.- São Paulo - SP

${ }^{2}$ Braf. Kodak Brasileira Com. e Ind. Ltda.

${ }^{3}$ Macrotec. Ind. e Com. de Equipamentos Ltda.
} 


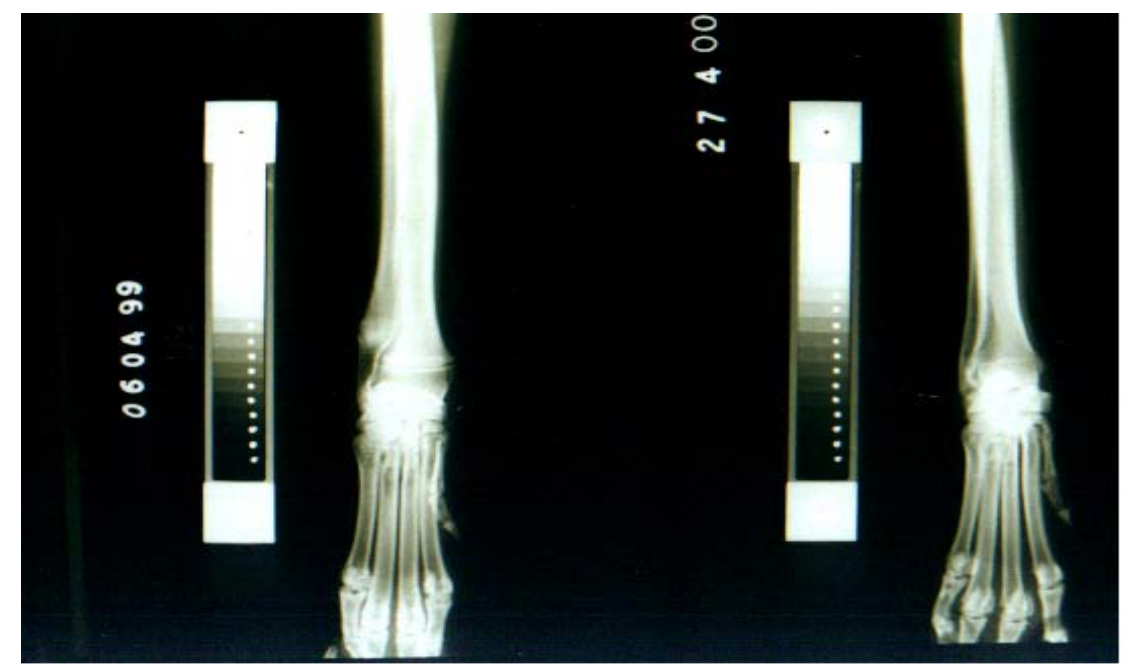

Figura 1. Exemplo de imagem radiográfica obtida do membro anterior direito, posicionado paralelo à escala de alumínio, em um animal do grupo-controle, no início e no final do experimento.

As radiografias foram encaminhadas ao setor de radiologia veterinária para as leituras densitométricas. Por meio de programa computacional $^{4}$, determinou-se a densidade mineral óssea da extremidade distal do rádio, em milímetros de alumínio (mmAl).

Para a comparação da densidade mineral óssea, foi realizada análise de variância. $\mathrm{O}$ momento um (M1) foi utilizado como covariável devido às diferenças no tamanho das fêmeas.

\section{RESULTADOS E DISCUSSÃO}

Houve redução na densidade óssea após a ovarioisterectomia nos animais do grupocontrole $(\mathrm{P}=0,022)$ (Fig. 2), o que confirma a semelhança na deterioração da microarquitetura óssea que, segundo Speroff et al. (1996), ocorre em mulheres após a menopausa.

Segundo Christiansen e Christensen (1981), a redução na massa óssea de mulheres na menopausa é de, aproximadamente, $7 \%$ nos primeiros três anos, e de $15 \%$ em 10 anos, valores confirmados pelo resultado deste estudo, em que quatro fêmeas do grupo $\mathrm{C}$ perderam, em média, $15 \%$ da densidade óssea inicial. Valores similares foram citados por Speroff et al. (1996),

\footnotetext{
${ }^{4}$ Athena - SAI, Sistema de inteligência avançada - SJC, SP
}

em um estudo de dois anos de duração, em mulheres na menopausa.

No grupo RH, houve discreta elevação nos valores da densidade óssea $(\mathrm{P}=0,09)$, em média $4 \%$ do valor inicial, resultados similares aos de Christiansen e Christensen (1981), que obtiveram aumento de 3 a 5\% na densitometria óssea de mulheres que receberam reposição estrogênica.

Trabalhos experimentais realizados em cães, mesmo utilizando técnicas de avaliação diferentes, demonstraram haver aumento na taxa de reabsorção/formação óssea em fêmeas castradas quando comparadas a animais intactos (Snow et al., 1984; Karambolova et al., 1987).

Quando fêmeas castradas foram submetidas à reposição de estrógeno por implantes subcutâneos, houve preservação da massa óssea (Snow e Anderson, 1985), aspecto confirmado neste experimento, em que a densidade óssea dos animais do grupo RH permaneceu estável durante o período de avaliação.

A dose de estrógenos naturais conjugados, considerada eficaz para a manutenção da massa óssea em mulheres, é de $0,625 \mathrm{mg}$ ao dia (Speroff et al., 1996; Sullivan, 1996), que foi a mesma dose adaptada para os animais deste estudo, conforme o peso individual. 


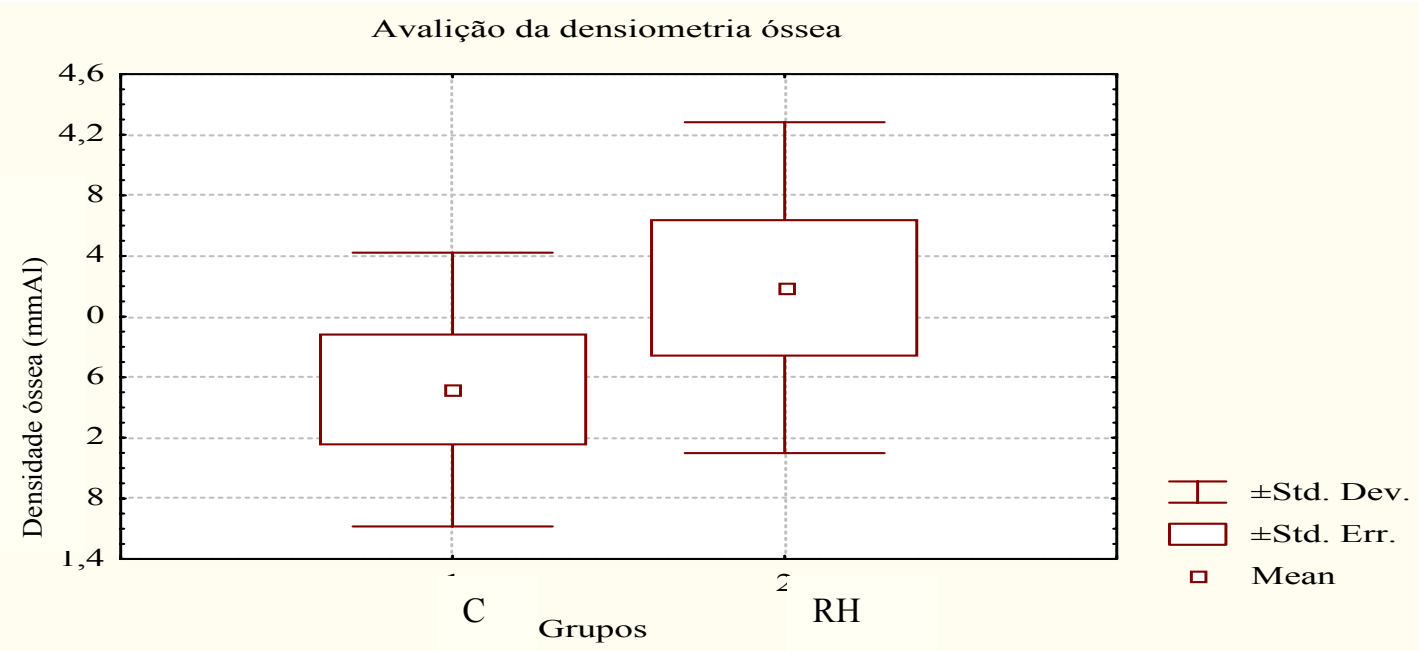

Figura 2. Médias, desvio-padrão e erro-padrão da média da densidade óssea em mmAl nos animais do grupo-controle (C) e de reposição hormonal (RH) para M2.

\section{CONCLUSÕES}

A ovarioisterectomia diminui a densidade mineral óssea em cadelas púberes, a qual é preservada pela reposição estrogênica após essa cirurgia.

\section{REFERÊNCIAS BIBLIOGRÁFICAS}

ARDILLA, E.A. Masa osea y menopausa. Rev. Col. Menop. Disponível em: <http://www. encolombia.com/meno33-estrogenoshtm>. v.3. Acessado em 15 fev 2001a.

ARDILLA, E.A. Osteoporosis senil vs. osteoporosis menopausica. Diagnostico y manejo. Rev. Col. Menop. Disponível em: $<$ http://www.encolombia.com/meno33estrogenos.htm>. v.3. Acessado em $15 \mathrm{fev}$ 2001b.

CHRISTIANSEN, C.; CHRISTENSEN, M.S. Bone mass in postmenopausal after withdrawal of oestrogen/gestagen replacement therapy. Lancet, v.28, p.459-461, 1981.

DANNUCCI, G.A.; PATTERSON, B.P. Ovariectomy and trabecular bone remodeling in the dog. Calcif. Tissues Int., v.36, p.568-590, 1987.
DOIGE, C.E.; WEISBRODE, S.E. Doenças dos ossos e articulações. In: CARLTON, W.D., McGAVIN, M.D. Patologia especial veterinária de Thomson. 2.ed. Porto Alegre: Artmed, 1998, p.448-485.

GARTON, M.J.; ROBERTSON, E.M.; GILBERT, F.J.et al. Can Radiologists detect osteopenia on plain radiographs? Clin. Radiol., v.49, p.118-122, 1994.

GRAY, J. Clinical evidence for postmenopausal hormone replacement therapy. Rev Soc. Cardiol. Est. São Paulo. Disponível em: $<\mathrm{http}: / /$ www.socesp.org.br/revistas/v6n6/htm>. v.6. Acessado em: 15 fev. 2001.

KARAMBOLOVA, K.K.; SNOW， G.R.; ANDERSON, C. Differences in periosteal and corticoendosteal bone envelope activities in spayed and intact beagles: a histomorphometric study. Calc. Tissue Int., v.37, p.665-668, 1985.

KARAMBOLOVA， K.K.; SNOW， G.R.; ANDERSON, C. Effects of continuous 17 $\beta$ estradiol administration on the periosteal and corticoendosteal envelope activitiy in spayed beagles. Calc. Tissue Int.. v.40, p.12-15, 1987.

KIRK, R.W. Atualização terapêtica veterinária. 2.ed. São Paulo: Manole, 1988. v.2, p.13191329. 
MALLUCHE, H.H.; FAUGERE, M.C.; RUSH, M. et al. Osteoblastic insufficiency is responsible for maintance of osteopenia after loss of ovarian function in experimental beagle dogs. Endocrinology, v.119, p.2649-2654, 1986.

PARRA, A.I.R. Estrogenos y homeostasis osea. Rev. Col. Menop. Disponível em: <http://www. encolombia.com/meno33-estrogeno.htm>. v.3. Acessado em:15 fev. 2001.

SNOW, G.R.; ANDERSON, C. The effects os continuous estradiol therapy on cortical bone remodeling activity in the spayed beagle. Calc. Tissue Int., v.37, p.437-440, 1985.
SNOW, G.R.; COOK, M.A.; ANDERSON, C. Oophorectomy and cortical bone remodeling in the beagle. Calc. Tissue Int., v.36, p.586-590, 1984.

SPEROFF, L.; ROWAN, J.; SYMONS, J. et al. The comparative effect on bone density, endometrium, and lipids of continuous hormones as replacement therapy. J. Am. Med. Assoc., v.6, p.1397-1403, 1996.

SULLIVAN, J.M. Estrogen replacement therapy. Am. J. Med., v.101, p.56S-60S, 1996. 